\title{
Umeclidinium/vilanterol versus fluticasone propionate/salmeterol in COPD: a randomised trial
}

\author{
Dave Singh ${ }^{1 *}$, Sally Worsley², Chang-Qing Zhu ${ }^{3}$ Liz Hardaker ${ }^{4}$ and Alison Church ${ }^{5}$
}

\begin{abstract}
Background: Umeclidinium (UMEC; long-acting muscarinic antagonist) plus vilanterol (VI; long-acting beta agonist $_{2}$ [LABA]) and the LABA/inhaled corticosteroid fluticasone propionate/salmeterol (FP/SAL) are approved maintenance treatments for chronic obstructive pulmonary disease (COPD). This 12-week, multicentre, double-blind, parallel-group, double-dummy study compared the efficacy and safety of these treatments in symptomatic patients with moderate-to-severe COPD with no exacerbations in the year prior to enrolment.
\end{abstract}

Methods: Patients ( $n=717$ ) were randomised 1:1 to once-daily UMECNI 62.5/25 mcg or twice-daily FP/SAL 500/50 mcg. Endpoints included 0-24 h weighted mean (wm) forced expiratory volume in $1 \mathrm{~s}\left(\mathrm{FEV}_{1}\right)$ (Day 84; primary), trough FEV (Day 85; secondary), other lung function endpoints, symptoms, quality of life (QoL) and safety.

Results: Improvements with UMECNI versus FP/SAL were 0.080 L (95 \% confidence interval: 0.046-0.113; wmFEV ${ }_{1}$ ) and $0.090 \mathrm{~L}\left(0.055-0.125\right.$; trough $\mathrm{FEV}_{1}$ ) (both $p<0.001$ ). UMECNI statistically significantly improved all other lung function measures versus FP/SAL. Both treatments demonstrated a clinically meaningful improvement in symptoms (Transition Dyspnoea Index $\geq 1$ unit) and QoL (St George's Respiratory Questionnaire Total score $\geq 4$ unit decrease from baseline) over 12 weeks. The incidence of adverse events was $28 \%$ (UMECNI) and $29 \%$ (FP/SAL); nasopharyngitis and headache were most common.

Conclusions: Once-daily UMECNI 62.5/25 mcg over 12 weeks resulted in significant and sustained improvements in lung function versus twice-daily FP/SAL 500/50 mcg in patients with moderate-to-severe COPD and with no exacerbations in the year prior to enrolment.

Trial Registration: NCT01822899 Registration date: March 28, 2013

\section{Background}

For the treatment of chronic obstructive pulmonary disease (COPD), Global Initiative for Chronic Obstructive Lung Disease ${ }^{\mathrm{Tw}}$ (GOLD) [1] recommends a management strategy based on assessment of the level of symptoms and degree of risk. There are four categories, with categories $\mathrm{C}$ and $\mathrm{D}$ including patients defined as higher risk than those in categories A and B, on the basis of severe airflow obstruction (i.e., forced expiratory volume in $1 \mathrm{~s}$ $\left[\mathrm{FEV}_{1}\right]<50 \%$ predicted) and/or a history of $\geq 2$

\footnotetext{
* Correspondence: dsingh@meu.org.uk

'University of Manchester, Medicines Evaluation Unit, Langley Building, University Hospital of South Manchester Foundations Trust, Southmoor Road, Manchester M23 9QZ, UK

Full list of author information is available at the end of the article
}

exacerbations (or $\geq 1$ leading to hospitalisation). Patients in categories $\mathrm{B}$ and $\mathrm{D}$ experience more symptoms than those in categories A and C.

Long-acting bronchodilators are the mainstay of COPD treatment as they improve lung function, and reduce symptoms and exacerbations [1]. Inhaled corticosteroids (ICS) are used to reduce exacerbations in patients with COPD with moderate-to-very severe airflow limitation, and there is good evidence for the efficacy of combination ICS/long-acting beta ${ }_{2}$ agonist (LABA) treatments in patients with a history of exacerbations (i.e., GOLD C and D patients) [1]. However, ICS are often prescribed to patients without a history of exacerbations and the evidence for efficacy in these 
patients is less compelling [2]; long-acting muscarinic antagonist (LAMA)/LABA therapies offer an alternative treatment option that may have a better benefit-risk profile in these patients. LAMA/LABA combination treatments are a recognised treatment option for GOLD B, C or D patients [1]; these treatments maximise lung function improvements by using two bronchodilators with different mechanisms of action to provide additive clinical benefits [3].

The LAMA/LABA combination umeclidinium (UMEC)/ vilanterol (VI), delivered via a single inhaler, is approved in the European Union, United States and several other countries as a once-daily maintenance treatment for COPD $[4,5]$. Studies in patients with COPD have shown that UMEC/VI is well tolerated and significantly improves lung function and symptoms versus placebo $[6,7]$ and versus long-acting bronchodilator monotherapy [6-8]. However, an important clinical question is how the efficacy of UMEC/VI compares with that of ICS/LABA combinations, which are often used in symptomatic patients with COPD who do not have a history of exacerbations (i.e., GOLD B and a subset of GOLD D patients).

The primary objective of this study was to compare the efficacy and safety of once-daily UMEC/VI (62.5/25 mcg) with twice-daily fluticasone propionate/salmeterol (FP/SAL) $(500 / 50 \mathrm{mcg})$ over 12 weeks in patients with COPD with dyspnoea and without exacerbations in the year prior to enrolment. FP/SAL is an established ICS/LABA therapy in COPD [9], and we hypothesised that UMEC/VI would be a more effective treatment in this particular group of patients. Preliminary results have been presented in abstract form [10].

\section{Methods \\ Patients}

The inclusion criteria were: male or female patients $\geq 40$ years old; an established COPD clinical history [1]; a

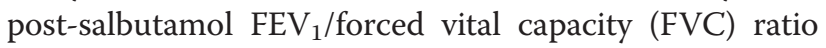
$<0.70$ and a post-salbutamol $\mathrm{FEV}_{1}$ of $\geq 30 \%$ and $\leq 70 \%$ of predicted normal values; a dyspnoea score of $\geq 2$ (modified Medical Research Council [mMRC] Dyspnoea Scale); current or former (stopped smoking for $\geq 6$ months) cigarette smokers with a history of cigarette smoking of $\geq 10$ pack-years. Key exclusion criteria were: asthma/ other respiratory disorders; hospitalisation for pneumonia within 12 weeks of screening; a documented history of $\geq 1$ COPD exacerbation requiring oral corticosteroids, antibiotics and/or hospitalisation in the 12 months preceding screening.

All patients provided written, informed consent prior to conducting any study-specific procedures. This study was approved by local ethics committees (Additional file 1) and performed in accordance with the Declaration of Helsinki [11] and Good Clinical Practice guidelines [12].

\section{Study design, randomisation and treatment}

This study (Additional file 2) was a phase IIIb, multicentre, randomised, double-blind, double-dummy, parallel-group trial (GSK study number DB2116134; www.clinicaltrials.gov registration number NCT01822899) conducted in 69 centres in eight countries (Czech Republic, Denmark, Germany, Hungary, The Netherlands, Poland, Russian Federation and Spain) between 2 April and 7 October 2013.

A validated computer system (RandAll; GSK, Brentford, UK) was used to generate a central randomisation schedule. Patients were randomised, using a Registration And Medication Ordering System (RAMOS; GSK, Brentford, UK), 1:1 to receive either UMEC/VI or FP/SAL. Patients and study personnel were blinded to the study medication.

After screening, eligible patients had a 7-14-day runin period, in which as-needed salbutamol, mucolytics and as-needed oxygen therapy ( $\leq 12 \mathrm{~h} /$ day) were the only permitted COPD treatments, for assessment of baseline salbutamol use and disease stability. Following randomisation, patients received either UMEC/VI $62.5 / 25 \mathrm{mcg}$ (delivered doses $55 / 22 \mathrm{mcg}$ ) via the ELLIPTA ${ }^{\circ 1}$ dry powder inhaler (DPI) once daily (morning) and placebo via the DISKUS ${ }^{\circ 2}$ inhaler (twice daily, morning and evening approximately $12 \mathrm{~h}$ apart) or FP/SAL 500/50 mcg via the DISKUS inhaler twice daily and placebo via the ELLIPTA DPI (once daily in the morning) for 12 weeks. There were further study visits at Weeks 4,8 and 12 (end of treatment), and a $7 \pm 2$ day follow-up safety assessment. Patients were permitted to use salbutamol for as-needed symptom relief throughout the study, as long as it was withheld in the $4 \mathrm{~h}$ prior to spirometry testing. Further details of restricted and permitted concomitant COPD medications are provided in the Additional file 3. Treatment compliance was assessed by reviewing the inhaler dose counters at each study visit.

\section{Outcome assessments \\ Efficacy (lung function) assessments}

Spirometry was conducted at each visit. Baseline spirometry assessments were recorded prior to randomisation, during the same study visit. The primary endpoint was change from baseline in weighted mean (wm) $\mathrm{FEV}_{1}$ over $0-24 \mathrm{~h}$ on Day 84, calculated from pre-dose $\mathrm{FEV}_{1}$ and post-dose $\mathrm{FEV}_{1}$ evaluations at 5 and $15 \mathrm{~min}$ and 1, 3, 6, 9, 12 (pre-evening dose), 13, 15, 18, 23 and $24 \mathrm{~h}$ after the morning dose. The secondary endpoint was change from baseline in trough $\mathrm{FEV}_{1}$ on Day 85 (i.e., the mean of the $\mathrm{FEV}_{1}$ values recorded $23 \mathrm{~h}$ and $24 \mathrm{~h}$ after morning dosing on Day 84). Other lung function endpoints included (change from baseline 
unless otherwise stated): peak $\mathrm{FEV}_{1}$ over $0-6 \mathrm{~h}$ post-dose on Days 1 and 84; time to onset (an increase of $\geq 0.100 \mathrm{~L}$ above baseline in $\mathrm{FEV}_{1}$ during $0-6 \mathrm{~h}$ post-dose on Day 1 ); proportion of patients achieving an increase in $\mathrm{FEV}_{1} \geq$ $12 \%$ and $\geq 0.200 \mathrm{~L}$ above baseline at any time during 0-6 h post-dose on Day 1; wmFVC 0-24 h post-dose on Day 84; trough FVC on Day 85; and wmFVC 0-6 h post-dose on Days 1 and 84. The proportion of patients achieving an increase in $\mathrm{FEV}_{1} \geq 0.100 \mathrm{~L}$ above baseline on Day 1 at 5 and $15 \mathrm{~min}$, and 1, 3 and 6 h post-dose was evaluated in a post hoc analysis.

\section{Symptomatic endpoints and health outcomes}

Patients completed daily diaries, including rescue medication use (puffs/day, percentage of rescue-free days were calculated). Dyspnoea was assessed using the Baseline Dyspnoea Index (BDI) focal score at baseline, and the Transition Dyspnoea Index (TDI) focal score on Days 28, 56 and 84. Quality of life was assessed using the St George's Respiratory Questionnaire for patients with COPD (SGRQ-C) at baseline and on Days 28 and 84. Health outcome assessments were evaluated using the EuroQol-5D (EQ-5D) questionnaire at randomisation and on Day 84. The COPD Assessment Test (CAT) was used to assess COPD-related health status at baseline and on Day 84 .

\section{Safety evaluations}

Safety and tolerability included monitoring adverse events (AEs) throughout the study. AEs were coded using the Medical Dictionary for Regulatory Activities. COPD exacerbations were recorded. Vital signs were evaluated on Days 1 and 84.

\section{Statistical analyses}

The sample size calculation was based on a two-sided $5 \%$ significance level and an estimated residual standard deviation of $0.220 \mathrm{~L}$ for $\mathrm{wmFEV}_{1}$ based on a mixed model for repeated measures (MMRM) analyses of previous studies in patients with COPD [6-8, 13]. Two hundred and eighty-four patients/group would have $90 \%$ power to detect a $0.060 \mathrm{~L}$ treatment difference in 0-24 h wmFEV $\mathrm{w}_{1}$. Assuming a $20 \%$ drop-out rate, approximately 710 patients (355/group) were to be randomised.

All analyses were conducted on the intent-to-treat population (all randomised patients who took at least one dose of study medication). To account for multiplicity across endpoints, a step-down, closed-testing procedure was used. If the primary endpoint was statistically significant at the $5 \%$ level, then the secondary endpoint was evaluated. If the latter was also statistically significant ( $5 \%$ level) then inferences at the $5 \%$ significance level would be made for all other comparisons.
An analysis of covariance (ANCOVA) model (covariates: baseline $\mathrm{FEV}_{1}$, smoking status and treatment) was used to analyse the $0-24 \mathrm{~h} \mathrm{wmFEV}_{1}$ on Day 84 . Trough $\mathrm{FEV}_{1}$ on Day 85 was analysed using MMRM analysis with covariates of baseline $\mathrm{FEV}_{1}$, smoking status, day, treatment, day by baseline interaction and day by treatment interaction, where day is nominal. The primary and secondary endpoints were also descriptively analysed by using the $\mathrm{FEV}_{1} \%$ predicted to categorise patients as GOLD B $\left(\mathrm{FEV}_{1} \geq 50 \%\right.$ predicted) or GOLD D $\left(\mathrm{FEV}_{1}<50 \%\right.$ predicted), as all patients were required to have an mMRC score $\geq 2$.

\section{Results}

\section{Study population}

Of 1009 patients enrolled, 870 were screened, 717 were randomised (Fig. 1), and 674 completed the study (UMEC/VI: 334; FP/SAL: 340). The most common reasons for withdrawal are shown in Fig. 1.

At baseline, patient demographics and characteristics were similar between groups (Table 1) and $55 \%$ and $45 \%$ of patients overall were categorised as GOLD B and $\mathrm{D}$, respectively. COPD medication taken pre-study is summarised in the Additional file 3.

Treatment compliance was approximately $100 \%$ in both treatment groups, and is summarised in the Additional file 3.

\section{Efficacy}

\section{Primary and secondary endpoints}

On Day 84, UMEC/VI caused a significantly greater improvement of $0.080 \mathrm{~L}$ (95\% confidence interval [CI]: $0.046-0.113 ; p<0.001)$ in the least squares (LS) mean change from baseline in $0-24 \mathrm{~h}$ wmFEV ${ }_{1}$ (primary endpoint) versus FP/SAL (Table 2). The increased effect of UMEC/VI compared with FP/SAL was also demonstrated in the $0-24 \mathrm{~h}$ serial $\mathrm{FEV}_{1}$ measurements on Day 84 (Fig. 2).

UMEC/VI statistically significantly improved the LS mean change from baseline in trough $\mathrm{FEV}_{1}$ on Day 85 (secondary endpoint) by 0.090 L (95 \% CI: 0.055-0.125; $p<0.001$ ) versus FP/SAL (Table 2, Fig. 3). Similar improvements were also seen on Days 28, 56 and 84 (Fig. 3).

Raw mean change from baseline for the primary and secondary endpoints was numerically greater in patients receiving UMEC/VI compared with $\mathrm{FP} / \mathrm{SAL}$ in both GOLD B and GOLD D patients, although no statistical analysis was performed (Table 3). Relative improvements in mean change from baseline with UMEC/VI versus FP/SAL were similar for GOLD B and GOLD D patients for both the primary $(0.085 \mathrm{~L}$ vs. $0.081 \mathrm{~L})$ and secondary (0.092 L vs. 0.094 L) endpoints. For both UMEC/VI and $\mathrm{FP} / \mathrm{SAL}$, the raw mean change from baseline for the 


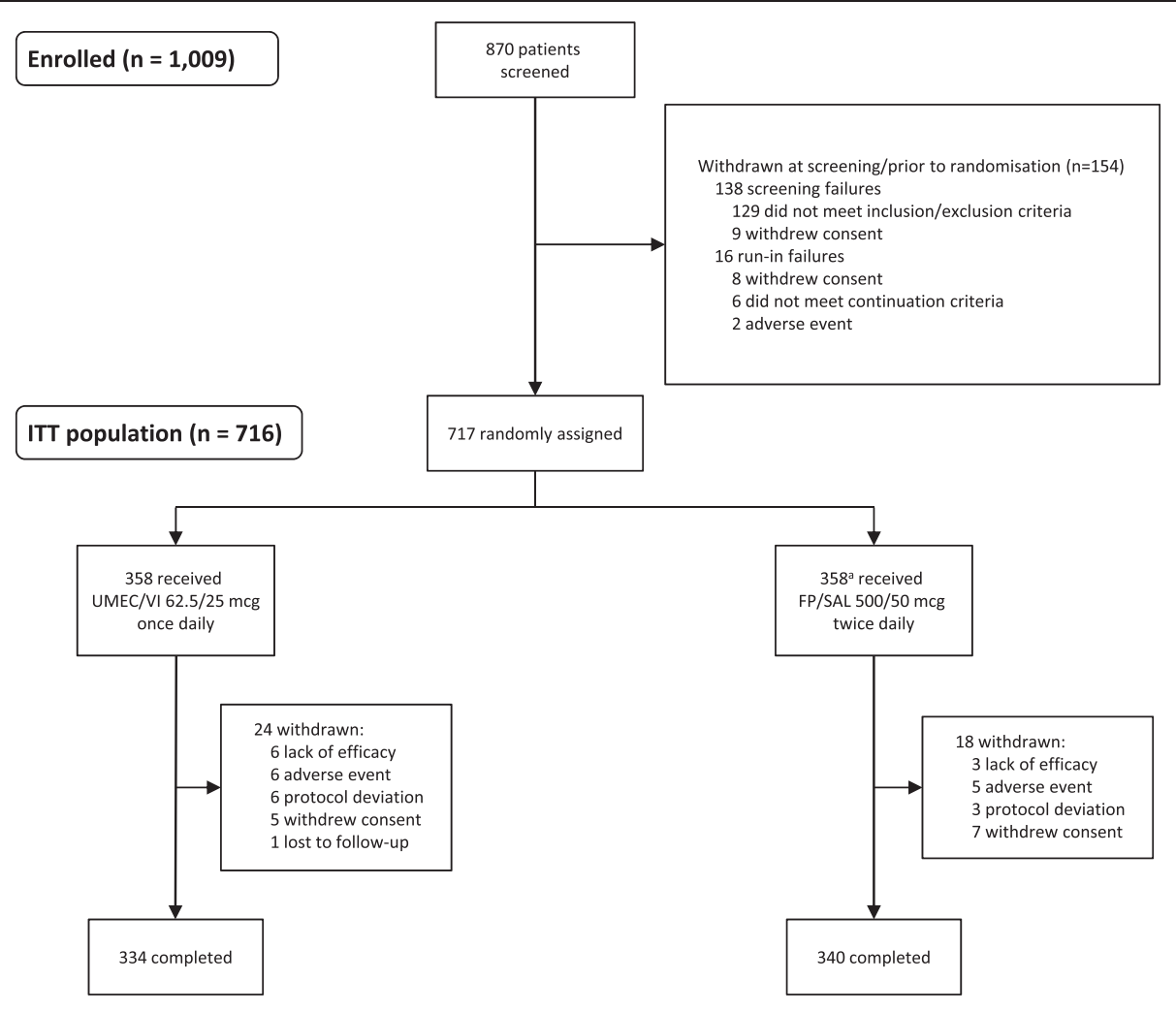

Fig. 1 Flow diagram for disposition of patients (CONSORT). Abbreviations: ITT, intent-to-treat; FP/SAL, fluticasone propionate/salmeterol; UMEC, umeclidinium; VI, vilanterol. ${ }^{\mathrm{O}}$ One patient was randomised in error; this patient was a run-in failure

primary and secondary endpoints was numerically greater in GOLD B compared with GOLD D patients.

\section{Other lung function endpoints}

For peak $\mathrm{FEV}_{1}$ over $0-6 \mathrm{~h}$ post-dose, statistically significantly greater improvements in LS mean change from baseline were seen with UMEC/VI versus FP/SAL on Days $1(p=0.003)$ and $84(p<0.001)$ (Table 2). Median time to onset on Day 1 (increase in $\mathrm{FEV}_{1} \geq 0.100 \mathrm{~L}$ above baseline) was significantly $(p=0.002)$ shorter with UMEC/VI compared with FP/SAL (Table 2). The proportion of patients achieving this increase in $\mathrm{FEV}_{1}$ on Day 1 was significantly greater $(p<0.05)$ with UMEC/VI versus FP/SAL at $5 \mathrm{~min}$ (Table 2), $15 \mathrm{~min}, 1,3$ and $6 \mathrm{~h}$ post-dose (Additional file 4). Patients treated with UMEC/VI had statistically significantly greater odds than patients treated with FP/SAL of achieving an increase from baseline in $\mathrm{FEV}_{1} \geq 12 \%$ and $\geq 0.200 \mathrm{~L}$ at any time during $0-6 \mathrm{~h}$ post-dose on Day $1(p=0.011)$, and in trough $\mathrm{FEV}_{1} \geq 0.100 \mathrm{~L}$ on Day $85(p<0.001$; Additional file 5), versus not achieving these increases.

UMEC/VI also significantly improved FVC endpoints (change from baseline in: wm $0-24 \mathrm{~h} F \mathrm{FV}$ on Day 84, trough FVC on Day 85, and wm 0-6 h FVC on Days 1 and 84) compared with FP/SAL (all $p<0.001$ ) (Additional file 6).

\section{Symptomatic endpoints and health outcomes}

No differences in rescue salbutamol use, mean TDI focal score, or SGRQ Total scores were seen between the UMEC/VI and FP/SAL groups at any time point (Table 4). UMEC/VI and FP/SAL resulted in clinically meaningful improvements in mean TDI scores ( $\geq 1$ unit focal score) at all time points and in SGRQ Total scores ( $\geq 4$ unit decrease from baseline) at all time points (except on Day 28 in the UMEC/VI group, where a 3.83-unit decrease was observed) (Table 4). The mean change from baseline on Day 84 for EQ-5D utility scores and CAT scores were similar for both treatments (Table 4).

\section{Safety assessments}

There were no unexpected safety findings with either treatment, and no marked differences were seen in the AE profiles between groups (Table 5). The incidence of cardiac AEs (2\% UMEC/VI; <1 \% FP/SAL) and pneumonia (0 \% UMEC/VI; $<1 \% \mathrm{FP} / \mathrm{SAL}$ ) was very low in 
Table 1 Baseline patient demographics, lung function and clinical characteristics (ITT population)

\begin{tabular}{|c|c|c|c|}
\hline & UMECNI 62.5/25 mcg $(N=358)$ & FP/SAL 500/50 mcg $(N=358)$ & Total $(N=716)$ \\
\hline Age, mean $\pm S D$, years & $61.8 \pm 7.94$ & $61.4 \pm 8.06$ & $61.6 \pm 8.00$ \\
\hline Sex: male, $n(\%)$ & $261(73)$ & $254(71)$ & $515(72)$ \\
\hline \multirow[t]{2}{*}{$\mathrm{BMI}$, mean $\pm \mathrm{SD}$ (range), $\mathrm{kg} / \mathrm{m}^{2}$} & $27.69 \pm 5.085$ & $27.26 \pm 5.018$ & $27.47 \pm 5.052$ \\
\hline & $(16.9-45.8)$ & $(15.6-44.4)$ & $(15.6-45.8)$ \\
\hline \multicolumn{4}{|l|}{ Race, $n(\%)$} \\
\hline White & $358(100)$ & $358(100)$ & $716(100)$ \\
\hline \multicolumn{4}{|l|}{ Smoking history and status } \\
\hline Current smoker, $n(\%)$ & $204(57)$ & $217(61)$ & $421(59)$ \\
\hline \multirow[t]{2}{*}{ Years smoked, mean \pm SD (range) } & $37.8 \pm 10.15$ & $37.7 \pm 10.27$ & $37.8 \pm 10.20$ \\
\hline & $(7-67)$ & $(10-70)$ & $(7-70)$ \\
\hline \multirow[t]{2}{*}{ No. cigarettes/day, mean \pm SD (range) } & $21.6 \pm 8.18$ & $20.8 \pm 7.72$ & $21.2 \pm 7.96$ \\
\hline & $(5-60)$ & $(7-80)$ & $(5-80)$ \\
\hline \multirow[t]{2}{*}{ Smoking pack years, mean \pm SD (range) } & $40.7 \pm 19.26$ & $39.4 \pm 19.09$ & $40.1 \pm 19.17$ \\
\hline & $(10-125)$ & $(10-140)$ & $(10-140)$ \\
\hline \multicolumn{4}{|l|}{ COPD history } \\
\hline \multicolumn{4}{|l|}{ Duration of COPD, $n(\%)$, years } \\
\hline$<1$ & $10(3)$ & $15(4)$ & $25(3)$ \\
\hline$\geq 1$ to $<5$ & $141(39)$ & $140(39)$ & $281(39)$ \\
\hline$\geq 5$ to $<10$ & $128(36)$ & $122(34)$ & $250(35)$ \\
\hline$\geq 10$ & $79(22)$ & $81(23)$ & $160(22)$ \\
\hline \multicolumn{4}{|l|}{ COPD type, $n(\%)^{a}$} \\
\hline Chronic bronchitis & $279(78)$ & $287(80)$ & $566(79)$ \\
\hline Emphysema & $189(53)$ & $180(50)$ & $369(52)$ \\
\hline \multicolumn{4}{|l|}{ Screening lung function, mean (SD) } \\
\hline Pre-salbutamol FEV $1, \mathrm{~L}$ & $1.423(0.4573)$ & $1.457(0.4555)$ & $1.440(0.4564)$ \\
\hline Post-salbutamol FEV $1, \mathrm{~L}$ & $1.550(0.4488)$ & $1.595(0.4614)$ & $1.572(0.4554)$ \\
\hline Pre-bronchodilator $\mathrm{FEV}_{1} / \mathrm{FVC}$ & $47.7(10.70)$ & $48.2(10.08)$ & $47.9(10.39)$ \\
\hline Post-salbutamol FEV $1 / F V C$ & $49.0(10.69)$ & $49.8(10.19)$ & $49.4(10.45)$ \\
\hline Post-salbutamol percent predicted FEV ${ }_{1},(\%)$ & $50.2(10.85)$ & $51.1(10.50)$ & $50.6(10.68)$ \\
\hline Percent reversibility to salbutamol, (\%) & $10.7(12.64)$ & $10.9(12.63)$ & $10.8(12.63)$ \\
\hline Reversibility to salbutamol, L & $0.127(0.159)$ & $0.138(0.154)$ & $0.133(0.157)$ \\
\hline Reversible to salbutamol, $n(\%)$ & $100(28)$ & $108(30)$ & $208(29)$ \\
\hline \multicolumn{4}{|l|}{ GOLD stage (percent predicted FEV $\left.{ }_{1}\right), n(\%)$} \\
\hline Stage B & $193(54)$ & $201(56)$ & $394(55)$ \\
\hline Stage D & $165(46)$ & $157(44)$ & $322(45)$ \\
\hline mMRC dyspnoea scale, mean (SD) & $2.2(0.41)$ & $2.2(0.42)$ & $2.2(0.41)$ \\
\hline \multicolumn{4}{|l|}{ Rescue salbutamol use } \\
\hline Puffs per day & $2.9(3.30)^{b}$ & $2.4(2.38)$ & - \\
\hline Rescue-free days (\%) & $24.4(35.01)^{\mathrm{b}}$ & $28.3(37.40)$ & - \\
\hline BDI focal score on Day 1 & $6.2(1.78)$ & $6.4(1.58)^{c}$ & - \\
\hline SGRQ Total score, mean (SD) & $46.57(16.523)^{d}$ & $44.02(15.756)^{b}$ & - \\
\hline EQ-5D utility score, mean (SD) & $0.70(0.213)$ & $0.75(0.191)$ & - \\
\hline CAT score, mean (SD) & $18.48(6.698)$ & $17.20(7.031)$ & - \\
\hline
\end{tabular}

$B D I$ baseline Dyspnoea Index, BMI body mass index, CAT COPD Assessment Test, COPD chronic obstructive pulmonary disease, EQ-5D EuroQol-5D questionnaire, FP/SAL fluticasone propionate/salmeterol, FEV 1 forced expiratory volume in $1 \mathrm{~s}, F V C$ forced vital capacity, GOLD Global initiative for chronic Obstructive Lung Disease, ITT intent-to-treat, $m M R C$ modified Medical Research Council, SD standard deviation, SGRQ St. George's Respiratory Questionnaire, UMEC umeclidinium, VI vilanterol

a Patients could select chronic bronchitis, emphysema or both; ${ }^{b} n=354 ;{ }^{c} n=356 ;{ }^{d} n=353$ 
Table 2 Results from the analyses of the primary, secondary and selected other endpoints (ITT population)

\begin{tabular}{|c|c|c|c|}
\hline Endpoint & UMEC/VI 62.5/25 mcg $(N=358)$ & & $\mathrm{FP} / \mathrm{SAL} 500 / 50 \mathrm{mcg}(\mathrm{N}=358)$ \\
\hline \multicolumn{4}{|l|}{ Primary endpoint } \\
\hline \multicolumn{4}{|l|}{ wm 0-24 h FEV 1 on Day 84, L } \\
\hline$n$ & 332 & & 337 \\
\hline LS mean (SE) & $1.618(0.0122)$ & & $1.539(0.0121)$ \\
\hline LS mean (SE) change from baseline & $0.166(0.0122)$ & & $0.087(0.0121)$ \\
\hline \multirow[t]{2}{*}{ Treatment difference (95 \% Cl) } & & $0.080(0.046-0.113)$ & \\
\hline & & $p<0.001$ & \\
\hline \multicolumn{4}{|l|}{ Secondary endpoint } \\
\hline \multicolumn{4}{|l|}{ Trough FEV ${ }_{1}$ on Day $85, \mathrm{~L}$} \\
\hline$n$ & 344 & & 353 \\
\hline$n^{\mathrm{a}}$ & 333 & & 338 \\
\hline LS mean (SE) & $1.600(0.0126)$ & & $1.511(0.0125)$ \\
\hline LS mean (SE) change from baseline & $0.151(0.0126)$ & & $0.062(0.0125)$ \\
\hline \multirow[t]{2}{*}{ Treatment difference (95 \% Cl) } & & $0.090(0.055-0.125)$ & \\
\hline & & $p<0.001$ & \\
\hline \multicolumn{4}{|l|}{ Other endpoints (selected) } \\
\hline \multicolumn{4}{|l|}{ Peak FEV ${ }_{1} 0-6 \mathrm{~h}$} \\
\hline \multicolumn{4}{|l|}{ Day 1} \\
\hline$n$ & 358 & & 358 \\
\hline$n^{\text {a }}$ & 358 & & 358 \\
\hline LS mean (SE) & $1.712(0.0083)$ & & $1.678(0.0083)$ \\
\hline LS mean (SE) change from baseline & $0.266(0.0083)$ & & $0.231(0.0083)$ \\
\hline \multirow[t]{2}{*}{ Treatment difference (95 \% Cl) } & & $0.034(0.011-0.057)$ & \\
\hline & & $p=0.003$ & \\
\hline \multicolumn{4}{|l|}{ Day 84} \\
\hline$n$ & 358 & & 358 \\
\hline$n^{\mathrm{a}}$ & 335 & & 340 \\
\hline LS mean (SE) & $1.773(0.0131)$ & & $1.676(0.0130)$ \\
\hline LS mean (SE) change from baseline & $0.327(0.0131)$ & & $0.229(0.0130)$ \\
\hline \multirow[t]{2}{*}{ Treatment difference $(95 \% \mathrm{Cl}$ ) } & & $0.097(0.061-0.134)$ & \\
\hline & & $p<0.001$ & \\
\hline \multicolumn{4}{|c|}{$\begin{array}{l}\text { Time to onset on Day } 1 \\
\text { (increase in } \mathrm{FEV}_{1} \geq 0.100 \mathrm{~L} \text { above baseline) }\end{array}$} \\
\hline$n$ & 358 & & 358 \\
\hline Median time to onset, min & 17 & & 60 \\
\hline \multirow[t]{2}{*}{ Hazard ratio $(95 \% \mathrm{Cl})$} & & $1.3(1.1-1.5)$ & \\
\hline & & $p=0.002$ & \\
\hline
\end{tabular}

Analysis of the primary endpoint was performed using ANCOVA with covariates of baseline FEV ${ }_{1}$, smoking status and treatment. Analysis of the secondary endpoint was by MMRM analysis including covariates of baseline $\mathrm{FEV}_{1}$, smoking status, day, treatment, day by baseline interaction and day by treatment interaction, where day is nominal

$\mathrm{Cl}$ confidence interval, $F E V_{1}$ forced expiratory volume in $1 \mathrm{~s}, F P / S A L$ fluticasone propionate/salmeterol, ITT intent-to-treat, $L S$ least squares, MRMM mixed-effect model repeated measure model, $S E$, standard error, UMEC umeclidinium, VI vilanterol, wm weighted mean

${ }^{a}$ Number of patients with analysable data at the current time point

both groups. Eight patients treated with UMEC/VI and three treated with FP/SAL experienced COPD exacerbations. Further safety results are provided in the Additional file 3.

\section{Discussion}

Once-daily UMEC/VI (62.5/25 mcg) for 12 weeks significantly improved all lung function endpoints compared with twice-daily FP/SAL (500/50 mcg) in patients 


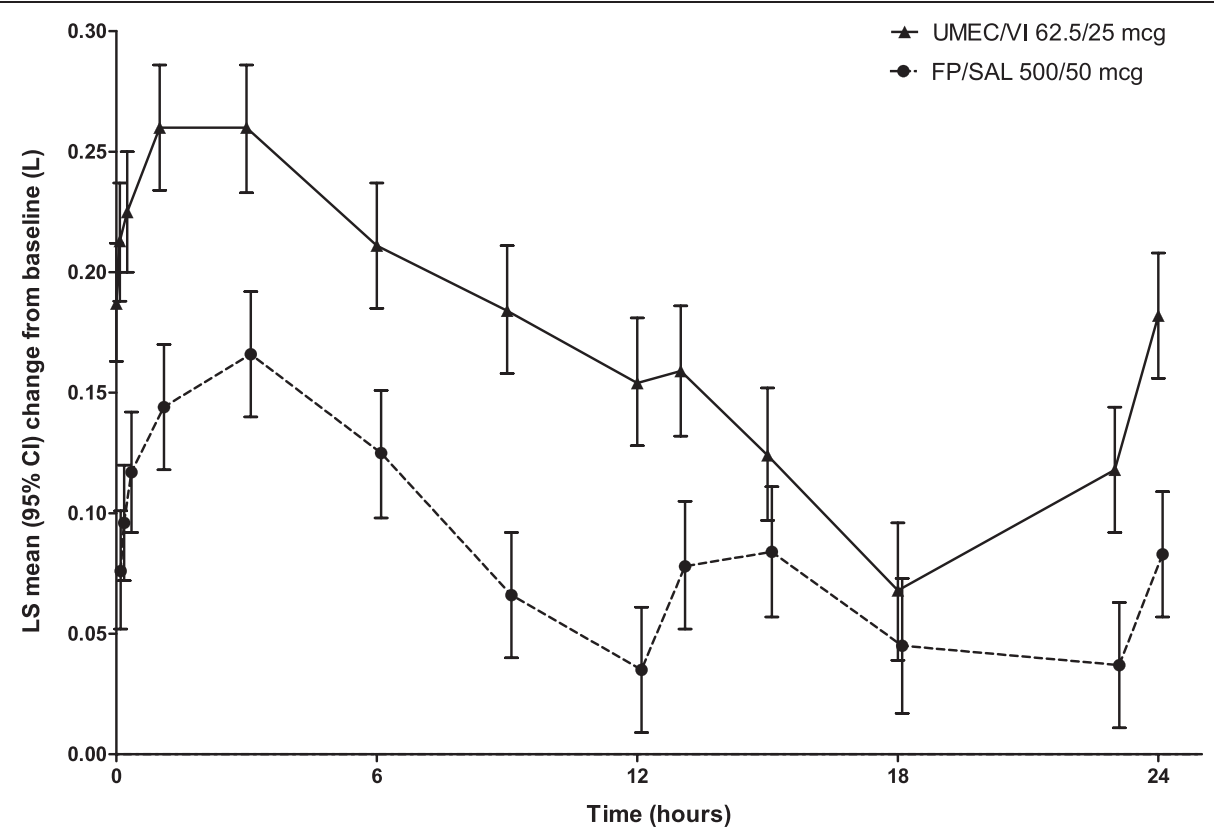

Fig. 2 Change from baseline in $\mathrm{FEV}_{1}(\mathrm{~L})$ over 0-24 h on Day 84 (ITT population). Data are least squares mean (95 \% Cl) change from baseline. Abbreviations: $\mathrm{Cl}$, confidence interval; $\mathrm{FEV}_{1}$, forced expiratory volume in $1 \mathrm{~S}$; ITT, intent-to-treat; LS, least squares; FP/SAL, fluticasone propionate/ salmeterol; UMEC, umeclidinium; VI, vilanterol

with moderate-to-severe COPD with dyspnoea who did not report an exacerbation in the year prior to enrolment. This study extends current understanding of the benefits of LAMA/LABA compared with ICS/LABA combination treatment regimens by comparing these treatments in GOLD B and a subgroup of GOLD D patients without a history of exacerbations in the year prior to enrolment.

In this study, patients with COPD with mMRC score $\geq 2$ and without a history of frequent exacerbations were categorised as either GOLD B ( $55 \%$ ) or D (45 \%) on the basis of lung function, according to GOLD [1]. Consistent with

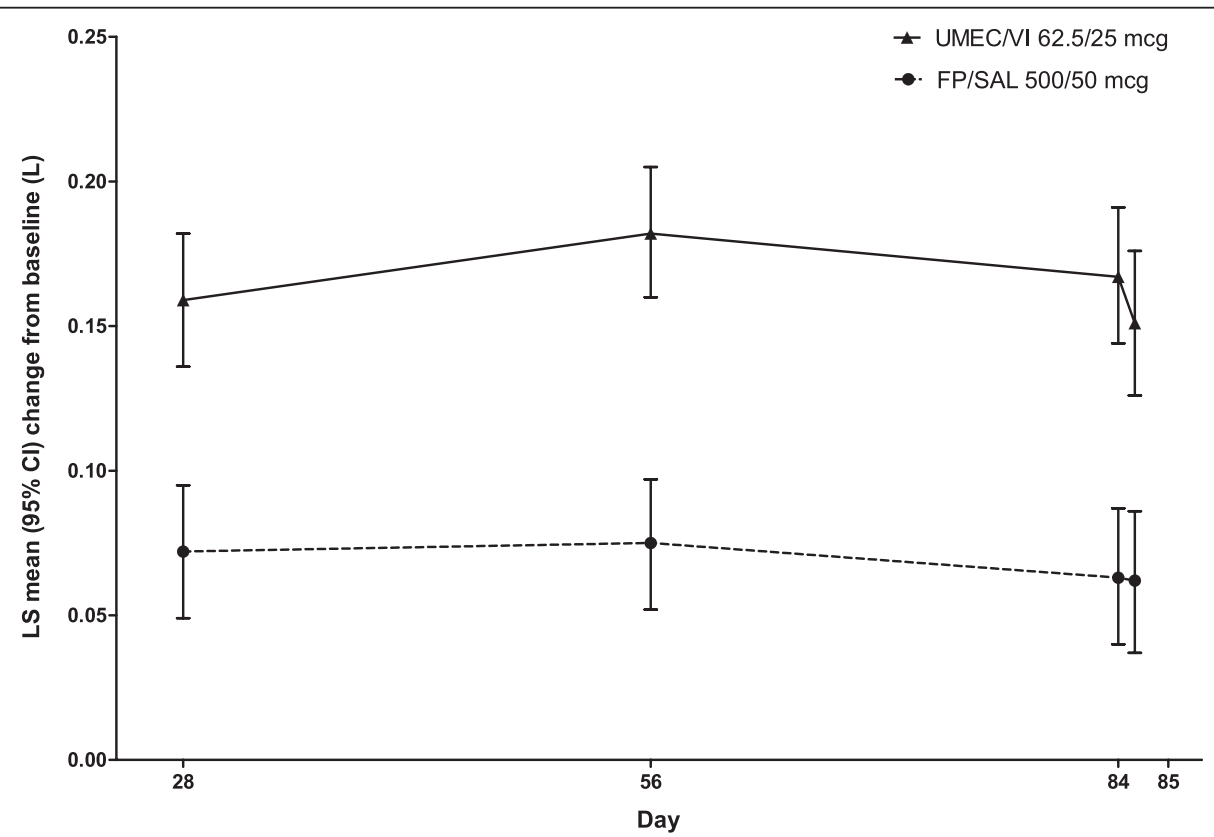

Fig. 3 Change from baseline in trough $\mathrm{FEV}_{1}(\mathrm{~L})$ (ITT population). Data are least squares mean ( $95 \% \mathrm{Cl}$ ) differences of change from baseline in trough $\mathrm{FEV}_{1}(\mathrm{~L})$ at Days 28, 56, 84 and 85. Abbreviations: $\mathrm{Cl}$, confidence interval; $\mathrm{FEV}_{1}$, forced expiratory volume in $1 \mathrm{~s}$; ITT, intent-to-treat; $L S$, least squares; FP/SAL, fluticasone propionate/salmeterol; UMEC, umeclidinium; VI, vilanterol 
Table 3 0-24 $\mathrm{h}$ wmFEV 1 and trough FEV 1 by GOLD subgroup (ITT population)

\begin{tabular}{|c|c|c|}
\hline Endpoint & UMECNI 62.5/25 mcg $(N=358)$ & $\mathrm{FP} / \mathrm{SAL} 500 / 50 \mathrm{mcg}(\mathrm{N}=358)$ \\
\hline \multicolumn{3}{|c|}{ 0-24 h wmFEV ${ }_{1}$ on Day 84, L, change from baseline } \\
\hline \multicolumn{3}{|c|}{ GOLD $B^{a, b}$} \\
\hline $\mathrm{n}$ & 184 & 189 \\
\hline mean (SD) & $0.181(0.2476)$ & $0.096(0.2230)$ \\
\hline \multicolumn{3}{|l|}{$G O L D D^{b, c}$} \\
\hline $\mathrm{n}$ & 148 & 148 \\
\hline mean (SD) & $0.152(0.2111)$ & $0.071(0.2038)$ \\
\hline \multicolumn{3}{|c|}{ Trough FEV 1 on Day 85, L, change from baseline } \\
\hline \multicolumn{3}{|c|}{ GOLD B B,b } \\
\hline $\mathrm{n}$ & 185 & 189 \\
\hline mean (SD) & $0.162(0.2661)$ & $0.070(0.2340)$ \\
\hline \multicolumn{3}{|l|}{$G O L D D^{b, c}$} \\
\hline $\mathrm{n}$ & 148 & 149 \\
\hline mean (SD) & $0.143(0.2067)$ & $0.049(0.2160)$ \\
\hline
\end{tabular}

Descriptive analyses of change from baseline in $0-24 \mathrm{~h}_{\text {wmFEV }}$ on Day 84 and in trough FEV $_{1}$ on Day 85 by GOLD subgroup

FEV 1 forced expiratory volume in $1 \mathrm{~s}, F P / S A L$ fluticasone propionate/salmeterol, GOLD Global Initiative for Chronic Obstructive Lung Disease ${ }^{\mathrm{TM}}$, ITT intent-to-treat, $S D$ standard deviation, UMEC umeclidinium, VI vilanterol, wm weighted mean

${ }^{\mathrm{a}} \mathrm{FEV}_{1} \geq 50 \%$ to $<80 \%$ predicted; ${ }^{\mathrm{b}}$ All but three patients fulfilled the exclusion criterion regarding no exacerbations in the past year-no further details of exacerbation history were collected; ${ }^{\mathrm{C}} \mathrm{FEV}_{1} \geq 30 \%$ to $<50 \%$ predicted

findings from other studies that have demonstrated decreased effectiveness of inhaled treatments in patients with COPD with worse lung function [14, 15], in a post hoc analysis the effectiveness of both treatments on the primary and secondary endpoints was observed to be numerically greater in GOLD B patients. However, the relative effectiveness of UMEC/VI and FP/SAL was similar in both GOLD categories.

A 6-week study in patients with moderate COPD demonstrated that the LAMA tiotropium (18 mcg once daily) in combination with the LABA formoterol $(12 \mathrm{mcg}$ twice daily), delivered via separate inhalers, significantly improved lung function compared with twice-daily FP/SAL (500/50 mcg) [16]. The ILLUMINATE study also demonstrated significant lung function improvements with once-daily QVA149 (glycopyrronium [a LAMA]/ indacaterol [a LABA] 50/110 mcg) versus twice-daily FP/SAL $(500 / 50 \mathrm{mcg})$ in patients with moderate-tosevere COPD without exacerbations in the previous year [17]. ILLUMINATE and our study demonstrate the potential clinical benefits of inhaled LAMA/LABA fixed-dose combination therapy in patients with COPD without frequent exacerbations. A key difference between ILLUMINATE and the present study was the higher proportion of patients with severe airflow obstruction (18\% vs. $45 \%$, respectively) in our study. Furthermore, we strictly defined patients as having increased symptoms using the mMRC Dyspnoea Scale as recommended by GOLD [14], and consequently the present study contains a significant proportion of GOLD D patients.
Both UMEC/VI and FP/SAL had a positive impact on symptomatic endpoints and health outcomes in our study. However, in contrast to the significantly greater lung function improvements seen with UMEC/VI versus FP/SAL, no treatment differences were seen for these endpoints. These findings are unexpected as improving lung function often has beneficial effects on such patient-reported outcomes in patients with COPD [18]. The lack of patient-reported health outcome benefits with UMEC/VI versus FP/SAL might suggest that current tools for measuring patient-reported outcomes are not sensitive enough within this sample size to detect differences between two active treatments. Another possible explanation is that 12 weeks is too short a duration to detect differences in patient-reported outcomes between treatments, and results from the 26-week ILLUMINATE trial [17] support this hypothesis.

While a numerical imbalance in COPD exacerbations was observed between treatment groups (8 [2\%] patients in UMEC/VI and $3[<1 \%]$ patients in FP/SAL), this was a small difference in a population with a very low exacerbation rate overall. Longer studies of UMEC/VI versus FP/SAL in a population with greater exacerbation risk are needed to clarify treatment differences on exacerbation rate between UMEC/VI and FP/SAL.

Overall, there were no new safety concerns with $\mathrm{UMEC} / \mathrm{VI}$ or FP/SAL and both treatments were well tolerated in our study, although the duration of treatment was relatively short (12 weeks). The tolerability profile with UMEC/VI in this study, particularly the very low incidence of cardiovascular effects, is similar to that 
Table 4 Results for symptomatic endpoints and health outcome measures (ITT population)

Endpoint

Rescue salbutamol use

Mean number of puffs/day, weeks 1-12

$n$

LS mean (SE)

LS mean (SE) change from baseline

Treatment difference $(95 \% \mathrm{Cl})$

Percent rescue-free days during 12 weeks, change from baseline

$n$

Mean (SD), (\%)

TDI focal score

$n^{\mathrm{a}}$

Day 28

$n$

LS mean (SE)

Treatment difference $(95 \% \mathrm{Cl})$

Day 56

$n$

LS mean (SE)

Treatment difference $(95 \% \mathrm{Cl})$

Day 84

$n$

LS mean (SE)

Treatment difference $(95 \% \mathrm{Cl})$

SGRQ Total score, change from baseline

$n^{\text {a }}$

Day 28

$n$

LS mean (SE)

LS mean change (SE)

Treatment difference $(95 \% \mathrm{Cl})$

Day 84

$n$

LS mean (SE)

LS mean change (SE)

Treatment difference (95\% Cl)

EQ-5D utility score on Day 84, change from baseline

$n$

Mean (SD)

UMEC/VI 62.5/25 mcg $(N=358)$

FP/SAL 500/50 mcg $(N=358)$

334

$1.3(0.08)$

$-1.3(0.08)$

$-0.1(-0.3-0.1)$

$p=0.559$

334

24.5 (36.38)

344

343

$1.7(0.13)$

$0.2(-0.2-0.5)$

$p=0.369$

336

$2.0(0.12)$

$0.3(0.0-0.6)$

$p=0.078$

334

$2.0(0.14)$

$-0.1(-0.4-0.3)$

$p=0.702$

339

337

$41.25(0.552)$

$-3.83(0.552)$

$1.22(-0.30-2.75)$

$p=0.116$

329

$39.98(0.626)$

$-5.10(0.626)$

$0.53(-1.20-2.26)$

$p=0.545$

335

$0.03(0.189)$
349

$1.4(0.08)$

$-1.2(0.08)$

349

23.5 (36.95)

351

350

$1.6(0.13)$

343

$1.7(0.12)$

338

$2.1(0.13)$

349

347

40.03 (0.544)

$-5.05(0.544)$

336

39.44 (0.619)

$-5.64(0.619)$

341

$0.03(0.203)$ 
Table 4 Results for symptomatic endpoints and health outcome measures (ITT population) (Continued)

\begin{tabular}{lll}
\hline CAT score on Day 84, change from baseline & 335 & 341 \\
$n$ & $-2.21(6.054)$ & $-2.35(6.432)$ \\
Mean (SD) &
\end{tabular}

CAT COPD Assessment Test, Cl confidence interval, EQ-5D EuroQoL-5D, FP/SAL fluticasone propionate/salmeterol, ITT intent-to-treat, $L S$ least squares, SE standard error, SD standard deviation, SGRQ St George's Respiratory Questionnaire, TDI Transition Dyspnea Index, UMEC umeclidinium, VI vilanterol

${ }^{a}$ Number of patients with analysis data for one or more time points

reported from other studies of longer duration in patients with COPD at the clinical dosing regimen (oncedaily $62.5 / 25 \mathrm{mcg}$ for 24 weeks) [7, 8]. Similarly, the FP/SAL tolerability data in our study are similar to those reported in previous studies [19-21].

A key strength of our study was the direct comparison of the approved UMEC/VI regimen with a commonly used ICS-based COPD treatment in patients specifically identified as GOLD B or D. Moreover, the study recruited approximately equal proportions of patients categorised as GOLD B or D. Other strengths include the large sample size, very high compliance with the study medications, and application of statistical hierarchy methodology to avoid multiple comparisons and multiplicity issues. Potential limitations of this study are that patient recruitment was restricted to
GOLD II and III patients, so the potential benefits of UMEC/VI compared with FP/SAL are unknown in very severe COPD, and that the study was insufficiently long to detect treatment differences in side effects.

\section{Conclusion}

Once-daily UMEC/VI 62.5/25 mcg over 12 weeks significantly improved lung function in symptomatic patients with moderate-to-severe COPD with no exacerbations in the year prior to enrolment versus twice-daily FP/SAL $500 / 50 \mathrm{mcg}$. ICS/LABA combinations are often prescribed to the type of patients enrolled in this study (GOLD B and GOLD D patients without frequent exacerbations). However, our findings indicate that the corticosteroid-sparing dual bronchodilator UMEC/VI may offer a better treatment option in these patients.

Table 5 Summary of incidence of different classes of AEs and COPD exacerbation (ITT population)

\begin{tabular}{|c|c|c|}
\hline & UMECNI 62.5/25 mcg $(N=358)$ & $\mathrm{FP} / \mathrm{SAL} 500 / 50 \mathrm{mcg}(\mathrm{N}=358)$ \\
\hline \multicolumn{3}{|l|}{$\mathrm{AEs}, n(\%)$} \\
\hline Any & $99(28)$ & $105(29)$ \\
\hline Treatment-related & $7(2)$ & $14(4)$ \\
\hline Leading to permanent discontinuation or withdrawal & $6(2)$ & $5(1)$ \\
\hline \multicolumn{3}{|l|}{ Serious AEs, $n(\%)$} \\
\hline Any & $7(2)$ & $2(<1)$ \\
\hline Treatment-related & 0 & 0 \\
\hline Fatal & $1(<1)$ & 0 \\
\hline \multicolumn{3}{|l|}{ AEs of special interest, $n(\%)$} \\
\hline Cardiac ischaemia ${ }^{a}$ & $3(<1)$ & 0 \\
\hline Cardiac arrhythmias & $3(<1)$ & $2(<1)$ \\
\hline Pneumonia & 0 & $1(<1)$ \\
\hline LRTI (excluding pneumonia) & $1(<1)$ & 0 \\
\hline \multicolumn{3}{|l|}{ AEs occurring in $\geq 3 \%$ patients in any treatment group, $n(\%)$} \\
\hline Headache & $33(9)$ & $25(7)$ \\
\hline Nasopharyngitis & $10(3)$ & $11(3)$ \\
\hline Back pain & $7(2)$ & $9(3)$ \\
\hline Dysphonia & $2(<1)$ & $9(3)$ \\
\hline COPD exacerbations, $n(\%)$ & $8(2)$ & $3(<1)$ \\
\hline
\end{tabular}

Summary of incidence of on-treatment AEs, serious AEs, AEs of special interest, most frequent AEs and COPD exacerbation

$A E$ adverse event, COPD chronic obstructive pulmonary disease, ITT intent-to-treat, $L R T I$ lower respiratory tract infection, FP/SAL salmeterol/fluticasone propionate, UMEC umeclidinium, VI, vilanterol

${ }^{a}$ All angina 


\section{Endnotes \\ ${ }^{1}$ ELLIPTA $^{\circ}$ is a trade mark of the GSK group of companies. \\ ${ }^{2}$ DISKUS $^{\circ}$ is a trade mark of the GSK group of companies.}

\section{Additional files}

\section{Additional file 1: List of institutions and Independent Ethics Committees/Institutional Review Boards for Study DB2116134. (DOC $122 \mathrm{~kb}$ )}

Additional file 2: Study design Figure. Abbreviations: BDI, Baseline Dyspnoea Index; CAT, COPD Assessment Test; FP/SAL, fluticasone propionate/salmeterol; $\mathrm{FEV}_{1}$, forced expiratory volume in $1 \mathrm{~s}$; ITT, intent-to-treat; mMRC, modified Medical Research Council SGRQ-C, St George's Respiratory Questionnaire for COPD; TDI, Transition Dyspnoea Index; UMEC, umeclidinium; VI, vilanterol. (PDF 425 kb)

Additional file 3: Online supplement. Online supplement containing additional details regarding COPD medications, treatment compliance and adverse events. (DOC $30 \mathrm{~kb}$ )

Additional file 4: Table S1. Proportion of patients achieving an increase $\mathrm{FEV}_{1} \geq 0.100 \mathrm{~L}$ above baseline at various times post-dose on Day 1 (ITT population; post hoc analyses). (DOC $38 \mathrm{~kb}$ )

Additional file 5: Table S2. Results from the analyses reporting proportions of patients achieving lung function improvements for selected other endpoints (ITT population). (DOC $37 \mathrm{~kb}$ )

Additional file 6: Table S3. Results from the analyses of FVC other endpoints (selected) (ITT population). (DOC 43 kb)

\section{Abbreviations}

AE: Adverse event; ANCOVA: Analysis of covariance; BDI: Baseline dyspnoea index; CAT: COPD assessment test; Cl: Confidence interval; COPD: Chronic obstructive pulmonary disease; $F_{E V}$ : Forced expiratory volume in $1 \mathrm{~s}$; FP/SAL: Fluticasone propionate/salmeterol; EQ-5D: EuroQol-5D; FVC: Forced vital capacity; GOLD: Global Initiative for Chronic Obstructive Lung Disease; ICS: Inhaled corticosteroids; ITT: Intent-to-treat; LABA: Long-acting beta, agonist; LAMA: Long-acting muscarinic antagonist; LS: Least squares; mMRC: Modified Medical Research Council; QoL: Quality of life; SGRQ-C: St George's Respiratory Questionnaire for COPD patients; TDI: Transition dyspnoea index; UMEC: Umeclidinium; VI: Vilanterol; wm: Weighted mean.

\section{Competing interests}

DS has served as consultant to Almirall, AstraZeneca, Boehringer Ingleheim, Chiesi, Cipla, GSK, Novartis, Nycomed and Roche; has received research grants from Almirall, AstraZeneca, Boehringer Ingleheim, Chiesi, Cipla, GSK, Novartis, Nycomed and Roche; has received payment for lectures including service on speakers bureaus from Almirall, AstraZeneca, Boehringer Ingleheim, Chiesi, Cipla, GSK, Novartis, Nycomed, Roche and Takeda. All other authors (SW, C-QZ, LH and AC) are employed by and hold stock in GSK.

\section{Authors' contribution}

DS contributed to the conception and design of the study and data interpretation. SW contributed to the conception and design of the study, acquisition of data and data interpretation. C-QZ contributed to the data analyses and data interpretation. LH contributed to the conception and design of the study and data interpretation. AC contributed to the conception and design of the study and data interpretation. Employees of the sponsor were involved in the conception, design and conduct of the study, and in data collection and analysis. All authors, including authors employed by the sponsor, participated in the development of the manuscript, and had access to the data from the study. The decision to submit for publication was that of the authors alone.

\section{Acknowledgements}

This study was sponsored by GSK. The authors wish to thank all patients and investigators involved in this study. We also thank Nathalie Richard (GSK), the statistician involved in protocol development and preparing the statistical analysis plan. Editorial support in the form of development of the draft outline and manuscript first draft in consultation with the authors, editorial suggestions to draft versions of this paper, assembling tables and figures, collating author comments, copyediting, fact checking, referencing and graphic services were provided by Jackie Phillipson, PhD at Gardiner-Caldwell Communications (Macclesfield, UK) and was funded by GSK. Further editorial support in the form of collating author responses to peer-review comments was provided by Gillian Groeger, PhD Fishawack Indicia (Abingdon, UK) and was also funded by GSK.

\section{Funding}

GSK (DB2116134).

\section{Clinical trial}

The study is registered at www.clinicaltrials.gov with identifier number NCT01822899; GSK study number DB2116134.

\section{Support statement}

This study was funded by GSK.

\section{Author details}

${ }^{1}$ University of Manchester, Medicines Evaluation Unit, Langley Building, University Hospital of South Manchester Foundations Trust, Southmoor Road, Manchester M23 9QZ, UK. 'Respiratory Medicines Development Centre, GSK, London, UK. ${ }^{3}$ Quantitative Sciences Division, GSK, London, UK. ${ }^{4}$ Global Clinical Safety and Pharmacovigilance, GSK, London, UK. ${ }^{5}$ Respiratory Medicines Development Center, GSK, Research Triangle Park, North Carolina, USA.

Received: 3 February 2015 Accepted: 4 August 2015 Published online: 19 August 2015

\section{References}

1. Global strategy for the diagnosis, management, and prevention of chronic obstructive pulmonary disease. http://www.goldcopd.org/guidelines-globalstrategy-for-diagnosis-management.html (2014). Accessed 17 Dec 2014.

2. Price D, West D, Brusselle G, Gruffydd-Jones K, Jones R, Miravitlles M, et al. Management of COPD in the UK primary-care setting: an analysis of real-life prescribing patterns. Int J Chron Obstruct Pulmon Dis. 2014;9:889-905.

3. Singh D. New combination bronchodilators for COPD: current evidence and future perspectives. Br J Clin Pharmacol. 2015;79:695-708.

4. Anoro EU summary of product characteristics, 16 May 2014. http://www. medicines.ie/medicine/16007/SPC/ANORO+55+micrograms+22+micrograms +inhalation+powder,+pre-dispensed/ (2014). Accessed 17 Dec 2014.

5. ANORO US prescribing information, May 2014. https://www.gsksource.com/ gskprm/htdocs/documents/ANORO-ELLIPTA-PI-MG.PDF (2014). Accessed 17 Dec 2014

6. Celli B, Crater G, Kilbride S, Mehta R, Tabberer M, Kalberg CJ, et al. Once-daily umeclidinium/vilanterol 125/25 mcg in COPD: a randomized, controlled study. Chest. 2014;145:981-91.

7. Donohue JF, Maleki-Yazdi MR, Kilbride S, Mehta R, Kalberg C, Church A. Efficacy and safety of once-daily umeclidinium/vilanterol $62.5 / 25 \mathrm{mcg}$ in COPD. Respir Med. 2013;107:1538-46.

8. Decramer M, Celli B, Kesten S, Lystig T, Mehra S, Tashkin DP. UPLIFT investigators. Effect of tiotropium on outcomes in patients with moderate chronic obstructive pulmonary disease (UPLIFT): a prespecified subgroup analysis of a randomised controlled trial. Lancet. 2009;374:1171-8.

9. Seretide EU summary of product characteristics. http://www.medicines. org.uk/emc/medicine/2317/SPC/Seretide+100,+250,+500+Accuhaler (2013). Accessed 17 Dec 2014.

10. Singh D, Worsley S, Zhu C-Q, Hardaker L, Church A. Umeclidinium/vilanterol (UMECNI) once daily (OD) vs fluticasone/salmeterol combination (FSC) twice daily (BD) in patients with moderate-to-severe COPD and infrequent COPD exacerbations. Eur Respir J. 2014;44 Suppl 58:P290.

11. World Medical Association Declaration of Helsinki - Ethical Principles for Medical Research Involving Human Subjects. Adopted by the 18th WMA General Assembly, Helsinki, Finland, June 1964 and amended (latest) by the 64th WMA General Assembly, Fortaleza, Brazil, October 2013. http://www. wma.net/en/30publications/10policies/b3/index.html (2008). Accessed 17 Dec 2014 
12. International Conference on Harmonisation Tripartite Guideline: Guidance for Good Clinical Practice E6 (R1). http://www.ich.org/fileadmin/Public_ Web_Site/ICH_Products/Guidelines/Efficacy/E6/E6_R1_Guideline.pdf (1996). Accessed 17 Dec 2014

13. Trivedi R, Richard N, Mehta R, Church A. Umeclidinium monotherapy in patients with COPD: a randomised, placebo-controlled study. Eur Respir J. 2014;43:72-81.

14. Jenkins CR, Jones PW, Calverley PM, Celli B, Anderson JA, Ferguson GT, et al. Efficacy of salmeterol/fluticasone propionate by GOLD stage of chronic obstructive pulmonary disease: analysis from the randomised, placebo-controlled TORCH study. Respir Res. 2009;10:59

15. Decramer M, Anzueto A, Kerwin E, Kaelin T, Richard N, Crater G, et al. Efficacy and safety of umeclidinium plus vilanterol versus tiotropium vilanterol, or umeclidinium monotherapies over 24 weeks in patients with chronic obstructive pulmonary disease: results from two multicentre, blinded, randomised controlled trials. Lancet Respir Med. 2014;2:472-86.

16. Rabe KF, Timmer W, Sagkriotis A, Viel K. Comparison of a combination of tiotropium plus formoterol to salmeterol plus fluticasone in moderate COPD. Chest. 2008;134:255-62.

17. Vogelmeier CF, Bateman ED, Pallante J, Alagappan VK, D'Andrea P, Chen H et al. Efficacy and safety of once-daily QVA149 compared with twice-daily salmeterol-fluticasone in patients with chronic obstructive pulmonary disease (ILLUMINATE): a randomised, double-blind, parallel group study. Lancet Respir Med. 2013;1:51-60.

18. Jones PW, Donohue JF, Nedelman J, Pascoe S, Pinault G, Lassen C. Correlating changes in lung function with patient outcomes in chronic obstructive pulmonary disease: a pooled analysis. Respir Res. 2011;12:161.

19. Calverley PM, Anderson JA, Celli B, Ferguson GT, Jenkins C, Jones PW, et al. TORCH investigators. Salmeterol and fluticasone propionate and survival in chronic obstructive pulmonary disease. N Engl J Med. 2007;356:775.

20. Celli BR, Thomas NE, Anderson JA, Ferguson GT, Jenkins CR, Jones PW, et al. Effect of pharmacotherapy on rate of decline of lung function in chronic obstructive pulmonary disease: results from the TORCH study. Am J Respir Crit Care Med. 2008;178:332-8.

21. Yawn BP, Raphiou I, Hurley JS, Dalal AA. The role of fluticasone propionate/ salmeterol combination therapy in preventing exacerbations of COPD. Int J Chron Obstruct Pulmon Dis. 2010:5:165-78.

\section{Submit your next manuscript to BioMed Central and take full advantage of:}

- Convenient online submission

- Thorough peer review

- No space constraints or color figure charges

- Immediate publication on acceptance

- Inclusion in PubMed, CAS, Scopus and Google Scholar

- Research which is freely available for redistribution 